\title{
Case Report: Prone Positioning and Nasal High Flow Oxygen Therapy - An Alternative Strategy to Invasive and Non-Invasive Ventilation in a Case of Severe Acute Respiratory Distress Syndrome
}

\author{
Orlando Rubén Pérez Nieto, \\ Ernesto Deloya Tomás,
} ICU. Hospital General San Juan del Río, Qro., México, Grupo AVENTHO Ventilación Mecánica

Karen Pamela Pozos Cortés, Jorge Hernández Zamudio, ICU. Hospital General San Juan del Río, Qro., México

Éder Iván Zamarrón López, ICU. Hospital Ángeles Tampico, Tamps., México, Grupo AVENTHO Ventilación Mecánica Raúl Soriano Orozco,

ICU. Unidad Médica de Alta Especialidad, Centro Médico Nacional del Bajío No.1 del IMSS, León, Gto., México, Grupo AVENTHO Ventilación Mecánica Miguel Ángel Martínez Camacho,

Maestría en Ciencias de la Rehabilitación en el Movimiento Humano, Universidad Autónoma de Querétaro, Grupo AVENTHO Ventilación Mecánica Jesús Salvador Sánchez Díaz,

ICU. Hospital de Especialidades No. 14, Centro Médico Nacional "Adolfo Ruiz Cortines"' del IMSS, Veracruz., México,

Grupo AVENTHO Ventilación Mecánica

Abstract

Acute respiratory distress syndrome (ARDS) is associated with high rates of mortality, which is directly attributed to the pulmonary inflammatory response then compromising gaseous exchange. This case study describes the successful management of a 63-year-old male with severe ARDS who received a strategy which involved the following interventions: Nasal High Flow Oxygen (NHFO) therapy, and prone positioning. It is thought that this 
strategy improved the lung volume at end expiration to an extent that the patient was able to avoid both noninvasive (NIV) and invasive mechanical ventilation (MV) (and their known associated risks). There is limited evidence describing the use of NHF therapy in patients with ARDS. The use of prone positioning has been demonstrated to significantly improve 28-day mortality in patients with severe ARDS with a $\mathrm{PaO}_{2} / \mathrm{FiO}_{2}<150 \mathrm{mmHg}$. The authors acknowledge that until such time that controlled clinical trials considering the efficacy of strategy are conducted it would be premature to recommend it forall suchcases. The prone position is a promising therapy for patients with spontaneous ventilation with high-flow oxygen therapy; controlled and randomized studies should be done to demonstrate its safety and efficacy.

Keywords: Acute distress respiratory syndrome; Prone position; Nasal High Flow Therapy

\section{Introduction}

Acute respiratory distress syndrome (ARDS), also known as an adult respiratory failure syndrome, is a life threating condition associated with antinflammatory response involving the lung parenchyma which significantly alters gas exchange decreasing $\mathrm{PaO}_{2}$. (Matthay et al., 2012).

In 1967 Ashbaugh reported a mortality of $70 \%$ for patients with ARDS, however more current evidence suggests a rate of between 40 and $50 \%$.Some of the randomized controlled trials have reported a higher increase in survival rates for select patient groups; likely due to the emergence of therapeutic strategies including: protective ventilation, the use of PEEP, the limitation of tidal volume, and fluid restriction (Matthay et al., 2012; Villar el al., 2014).

At a pathophysiological level, ARDS is an acute diffuse inflammatory response, that generates the activation of macrophages and mobilization of pro-inflammatory cytokines; in particular, the alpha tumoral necrosis, interleukins, and pro-coagulant factors, which collectively then activate the waterfall of coagulation producing microthrombosis. Conversely, the complement is activated and there is migration of polymorphonuclear neutrophils from the capillaries to the intersticial tissue and the alveoli, which damages the tissue through reactive species of oxygen and proteases; this generates pulmonary edema which alters the gaseous exchange, increased physiological dead space, and decreased lung compliance (Lam et al., 2008; Smith et al., 2013; Capelozzi et al., 2008).

ARDS may be classified according to the diagnostic criteria (Villar et al., 2011; Costa et al., 2013; Ranieri et al., 2012): 
1) Acute onset within of a defined event within 7 days e.g. sepsis.

2) Bilateral opacities consistent with pulmonary edema, which may be detected on CT or chest X Ray.

3) Respiratory failure not completely explained by cardiac failure or fluid over load (requiring an objective study, e.g. echocardiography) to exclude hydrostatic edema.

The severity of ARDS with PEEP or CPAP $>5 \mathrm{cmH}_{2} \mathrm{O}$ is classified as follows: $\mathrm{PaO}_{2} / \mathrm{FiO}_{2}$ of 200 to $300 \mathrm{mmHg}$ (mild ARDS), 100 to $200 \mathrm{mmHg}$ (moderate ARDS), and $<100 \mathrm{mmHg}$ (severe ARDS).

The characteristic signs and symptoms are: hypoxemic respiratory failure with progressive dyspnea, nasal flaring, and thoracoabdominal asynchrony.

The principal characteristic of this syndrome is refractory hypoxemia whilst on conventional treatment, which may improve with the use of MV, NIV or NHFO. There is some debate regarding the preventative or curative use of these respective therapies (Jaber et al., 2010). However, most patients with moderate to acute ARDS will require either NIV or MV to maintain optimal levels of oxygenation. It has been recently hypothesized that either Volume and or Patient self-inflicted lung injury (VILI and p-SILI) may contribute to the adverse events seen with the high respiratory drive associated with ARDS (Mancebo, 2016). In addition, for those with ARDS and $\mathrm{PaO}_{2} / \mathrm{FiO}_{2}$ of $<150 \mathrm{mmHg}$ prone positioning has been seen to significantly reduce mortality.

\section{Nasal high flow oxygen therapy}

Oxygen therapy is the first treatment choice for patients with acute hypoxemic respiratory failure (type 1) (O`Driscoll, 2012). It is normally delivered through nasal cannula or a face mask with or without a reservoir; however, the oxygen flow through these devices is limited to $<15 \mathrm{~L} / \mathrm{min}$.In addition, the supplied oxygen is often diluted with room air, due to the failure of the device to meet the patient's required inspiratory demand (Kallstrom, 2002). This means that the higher the inspiratory demand, the higher the dilution, of note these gases are not heated or humidified. A patient with mild respiratory failure may benefit from low flow oxygen therapy; however, patients with moderate to severe respiratory failure may have an inspiratory demand from 30 to $120 \mathrm{~L} / \mathrm{min}$, necessitating the use of devices able to supply these demands. There are specialist nasal cannula which can provide oxygen therapy (from 21 to $100 \%$ ) at flows of up to $60 \mathrm{~L} / \mathrm{min}$ at optimal heat and humidity (relative humidity 95 to $100 \%$, heated 31 to $37^{\circ} \mathrm{C}$ ); this therapy is known as Nasal High Flow Oxygen therapy (NHFO)(Pilar et al., 2014). 
There is a substantial amount of favorable evidence about the use of NHFO therapy across all age groups: neonatal, infant, pediatric and patients. In recent years this therapy has been studied on adult patients, in multiple clinical scenarios, including but not limited to the following conditions:

- Respiratory failure

- Mechanical ventilation weaning strategy

- Procedural sedation

- Peri intubation

- Acute respiratory distress syndrome

- Acute cardiac failure

- Chronic cardiac failure

- Pre-intubation oxygenation

- Obstructive sleep apnea

- Chronic obstructive pulmonary disease (COPD).

\section{NHFO and ARDS}

The evidence regarding NHFO and ARDS is emerging and conflicting, and most is retrospective. Messika and colleagues (2018), concluded that NHFO may be considered as first-line therapy in ARF. Roca and colleagues (2016) proposed that those at risk for ARDS, NHF may achieve success rates similar to those seen with NIV. There are collection of case series e.g Medina et al (2015) in which it was observed that NHFO was not beneficial for morbidity and mortality outcomes in patients with severe ARDS. In cases of mild to moderate hypoxemia, both NIV and NHFO have proven to be acceptable alternatives before committing to MV.

\section{Mechanisms of action}

NHFO has a series mechanisms of action that collectively may help to resolve the work of breathing and improve outcomes.

\section{Respiratory support:}

- Continuous dynamic positive airway pressure. NHFO generates a continuous dynamic pressure in the airway, which increases the residual functional capacity, decreases atelectasis, and improves the ventilation-perfusion pulmonary ratio (Parke et al., 2009).

- Wash out of the anatomical dead space (Möller et al., 2015)

- The deadspace washout is linearly related to the rate of delivered flow NHFO. Clearance of the nasal component of the anatomical deadspace with NHFO therapy, significantly reduces $\mathrm{CO}_{2}$ rebreathing and WOB. 


\section{$\mathrm{O}_{2}$ delivery}

There is an opertunity to accurately titrate the $\mathrm{FiO}_{2}$ delivered to match the patients needs (Parke et al., 2011).

\section{Patient comfort}

Nasal gases - when heated and humidified, are better tolerated, especially at high flows which ensures compliance (Maggiore et al., 2014).

\section{Prone position}

Prone positioning was first described in the literature by Bryan and colleagues (1974), who highlighted a potential favorable impact upon pulmonary mechanics. Piehl et al.(1976) then also reported a significant improvement in oxygenation. A third study - by Douglas (1977) hypothesized on the benefits of the prone positioning for patients with ARDS. Despite the reported improvement described in these studies, none demonstrated statistical significance, consequently they have been often disregarded by the clinical community (Gattinoni et al., 2013).

Then in 2013, a French multi-center study demonstrated, a significant benefit for mortality rates at 28 days: $16 \%$ for prone positioning group (38/237 patients) versus $32.8 \%(75 / 229$ patients) in the control group ( $p<0.0001)$. It must be noted that the included patients had $\mathrm{PaO}_{2} / \mathrm{FiO}_{2}$ of $<150 \mathrm{mmHg}$ and were managed with protective mechanical ventilation and neuromuscular agents (Guérin et al., 2013).

\section{Nasal High Flow Oxygen therapy and body positioning}

A Spanish study using NHFO therapy enrolling 20 healthy patients demonstrated an increase in the lung volume at the end of expiration (LVEE), and associated with changes in body position. This research demonstrated that in supine and prone positions an increase in the LVEE may be achieved, a decrease in the RR with no associated adverse effects were also seen. A more homogenous LVEE was also seen with electric impedance tomography (EIT), in prone position (Riera et al., 2012).

As a result of these findings, the authors decided to employ a combined strategy of the prone positioning with NHFO therapy, with the aim of improving clinical outcomes for severe ARDS patients.

\section{Presenting the clinical case}

The authors present a case of a 63-year-old male patient, with a history of chronic smoking (35 packets per year), chronic alcoholism, with no other comorbid conditions. The patient presented at the hospital with respiratory distress, somnolence, asthenia, adynamia, fever, dry cough, arthralgias, myalgias, and a history ofrunny nose and sneezing for at least 7 days prior to 
his admission. In the emergency department (ED) his respiratory rate (RR) was 40 to 45 breaths per minute, $\mathrm{SpO}_{2} 68$ to $87 \%$, (on $\mathrm{O}_{2}$ through a face mask $10 \mathrm{~L} / \mathrm{min}$ ). Nebulized salbutamol, ipratropium, and broad-spectrum antibiotics Ceftriaxone, noclinical improvement was seen. X-rays showed bilateral radiolucent pictures suggestive of generalized severe pneumonic process (image 3).

The $\mathrm{ABG}$ on admission showed $\mathrm{PaO}_{2} 49 \mathrm{mmHg}, \mathrm{PCO}_{2}$ of $40 \mathrm{mmHg}$, $\mathrm{HCO}_{3}$ of 27.3,pH of 7.44, (on $\mathrm{O}_{2}$ via face mask at $10 \mathrm{~L} / \mathrm{min}$ ). The $\mathrm{FiO}_{2}$ was calculated at between 40 and $60 \%$, with which the $\mathrm{PaO}_{2} / \mathrm{FiO}_{2}$ was calculated at $85 \mathrm{mmHg}$ for this patient, adapted to the altitude of $1,920 \mathrm{~m}$ above sea level at which the city of San Juan del Rio, Queretaro, is located. With a barometric pressure of $568 \mathrm{mmHg}$, the adjusted $\mathrm{PaO}_{2} / \mathrm{FiO}_{2}$ was determined at $63 \mathrm{mmHg}$ with leukocytes $19 \times 10^{3}$, urea $143 \mathrm{mg} / \mathrm{dl}$, and creatinine $1.46 \mathrm{mg} / \mathrm{dl}$. An ICU assessment was requested 24 hours after his entry to the ED. Staff were informed that the patient was not intubated as there was no mechanical ventilator available during the patient's stay in the ED. He was then transferred to the ICU, as soon as the ABG were assessed and a provisional diagnosis ARDS and non-exacerbation COPD was made There was no presence of purulent expectoration or acute respiratory acidosis; however, he presented with a tendency for metabolic alkalosis probably associated with a renal compensation post chronic respiratory acidosis.

On admission to the ICU, he had RR 40, was agitated, with intercostal, subcostal, supraclavicular, and cervical retraction, $\mathrm{ABG}: \mathrm{PaO}_{2}$ of $52 \mathrm{mmHg}$, $\mathrm{PaCO}_{2}$ of $52 \mathrm{mmHg}$, pH of $7.3, \mathrm{HCO}_{3}$ of $23.1 \mathrm{mmol} / \mathrm{L}$, and $\mathrm{SaO}_{2}$ of $82 \%$.With a diagnosis of respiratory acidosis and severe ARDS, a ground-glass image was observed covering 3/4 of both lungs, bilateral air bronchogram and bilateral pleural effusion were also observed.

\section{Intervention}

With a diagnosis of a severe hypoxemic RF, hypercapnia, and respiratory acidosis, the decision was made to trial NHFO therapy at $60 \mathrm{~L} / \mathrm{min}$ and an $\mathrm{FiO}_{2}$ at $100 \%$. The respiratory WOB improved immediately with decreased RR to 35 and improved the $\mathrm{SpO}_{2}$ from $82 \%$ to $92 \%$. With informed consent from the patient he was placed in a decubital prone position. The patient was placed in prone position with the help of a physician, a nurse, and a hospital stretcher, and an abrupt improvement in $\mathrm{SpO}_{2}$ 97\% was shown and the RR decreased to 27. Hewas informed that he could move tolerated, but to always maintain the prone position.A comparative $\mathrm{ABGwas}$ taken an hour after the position change, which showed: $\mathrm{pH} 7.33, \mathrm{PaO}_{2} 60 \mathrm{mmHg}, \mathrm{PaCO}_{2} 55$ $\mathrm{mmHg}, \mathrm{SaO}_{2} 89 \%, \mathrm{HCO}_{3}$ 25.8. The patient was placed under close surveillance and his respiratory mechanical pattern, heart rate, RR, urine output, and level of consciousness continued to remain stable. The patient 
remained closely monitored with a view to proceed with an immediate intubation if. However, the patient's condition continued to steadily improve with the NHFO and prone positioning strategy. Fluid restriction was commenced, in addition to the following medications: Oseltamivir $75 \mathrm{mg}$ every $12 \mathrm{~h}$, Levofloxacino $750 \mathrm{mg}$ IV every $24 \mathrm{~h}$, Ceftriaxone $2 \mathrm{~g}$ IV every 24 h, metilprednisone IV $1 \mathrm{mg} / \mathrm{kg}$ every $24 \mathrm{~h}$, glycemic control targeting 110 to $180 \mathrm{mg} / \mathrm{dl}$, Enoxaparina $1 \mathrm{mg} / \mathrm{kg} \mathrm{SC}$ every $24 \mathrm{~h}$, and Omeprazol $40 \mathrm{mg} \mathrm{IV}$ every $24 \mathrm{~h}$.

The patient was kept prone for 4 hours in a swimmer position, moving as tolerated exchanging the elevation of the left and right arms with head ipsilateral lateralization; later, the patient was returned to a semi-fowler position. Pulmonary physiotherapy and he remained closely monitored for any changes. The prone position was repeated the following days with the same scheme during the morning shift, in the afternoon and night shifts the patient remained in the semi-fowler position, alternating with decubital left and right lateral as tolerated, and a larger draining of secretions was observed with the pulmonary physiotherapy in prone position. We can see the progression of the patient during the ICU stay in the X-rays and tomography (image 2 and 3 ).

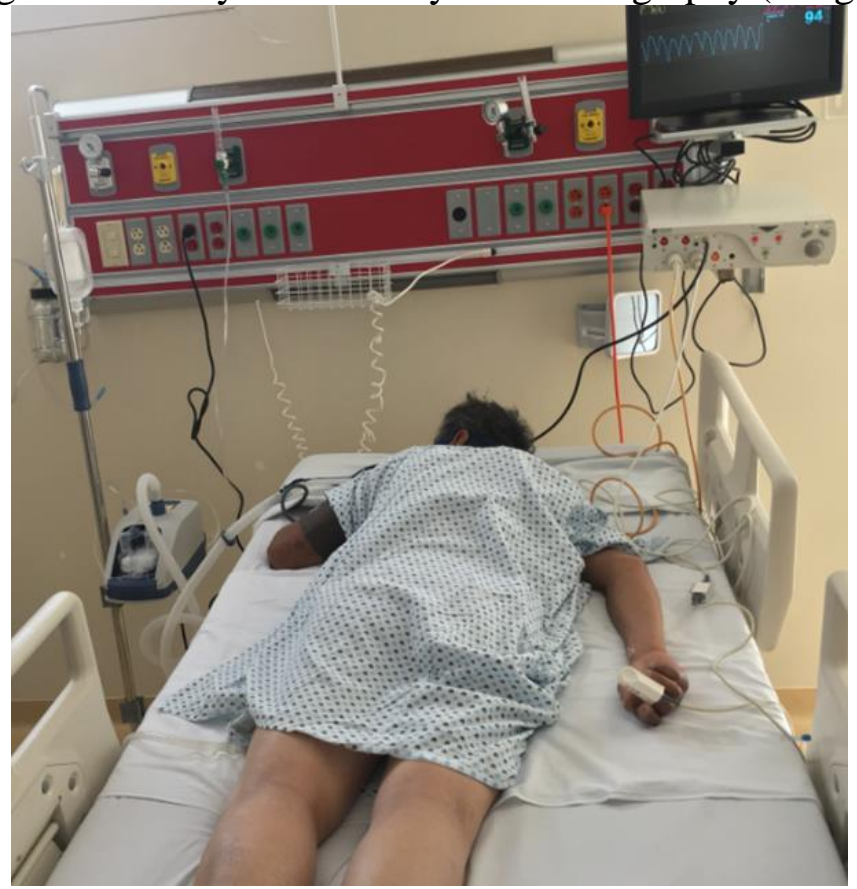

Image 1. Prone position with high flow oxygen therapy.

The patient showed bleeding from the nasogastric tube, and an endoscopy was performed, during which he received NHFO therapy without any complications. In order to exclude cardiac contributor to this acute event, a transthoracic echocardiogram was performed. Systolic cardiac failure was 
not demonstrated, however the left ventricular ejection fraction was $62 \%$, along with severe pulmonary arterial hypertension, and mild tricuspid failure. Sildenafil was commenced.

The patient kept the prone position 4 hours each morning for 5 days. After that period, he was maintained in semi-fowler position with frequent mobilization, continued on NHFO therapy for 14 days. The NHFO FiO 2 was titrated to a target $\mathrm{SaO}_{2}>88 \%$ and absence of dyspnea, the flow was kept at between 60 and $40 \mathrm{~L} /$ min the first 12 days, during which the required $\mathrm{FiO}_{2}$ approximately $60 \%$.On two occasions the $\mathrm{FiO}_{2}$ was required to be increased to $100 \%$. On day 12 in the ICU the flow was successfully reduced to 35 to 30 $\mathrm{L} / \mathrm{min}$ after 12 hours, and on the day 13 it was reduced to 25 to $20 \mathrm{~L} / \mathrm{min}$ after 12 hours and a decrease in the $\mathrm{FiO}_{2}$ from 40 to $30 \%$.On day 14 the NHFO therapy was stopped, with a pulse-oximetry $\mathrm{SpO}_{2}$ of $95 \%$, and the patient was given low-flow standard oxygen therapy without complications. He left the ICU 7 days after ceasing the NHF therapy, with no evidence of systemic inflammatory response, or organ dysfunction. The evolution in gasometrical parameters during his stay in the ICU is shown in image 4.
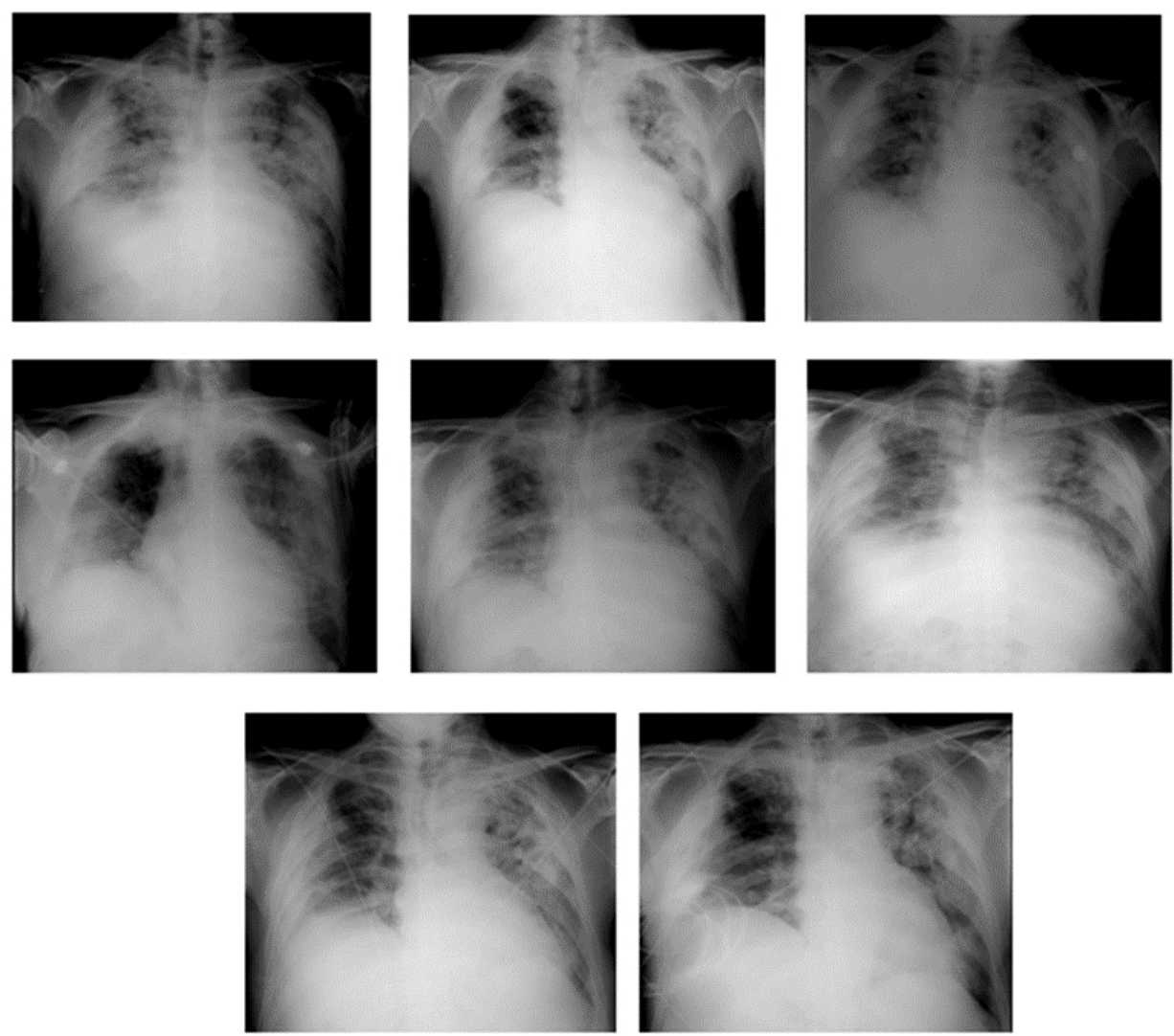

Image 2. Anterior-posterior X-rays performed in portable way during the internment of the patient in the ICU that shows the radiographic evolution since the entry of the patient until his egress from the ICU. 
1. Simple thorax computed tomography at the patient's entry.
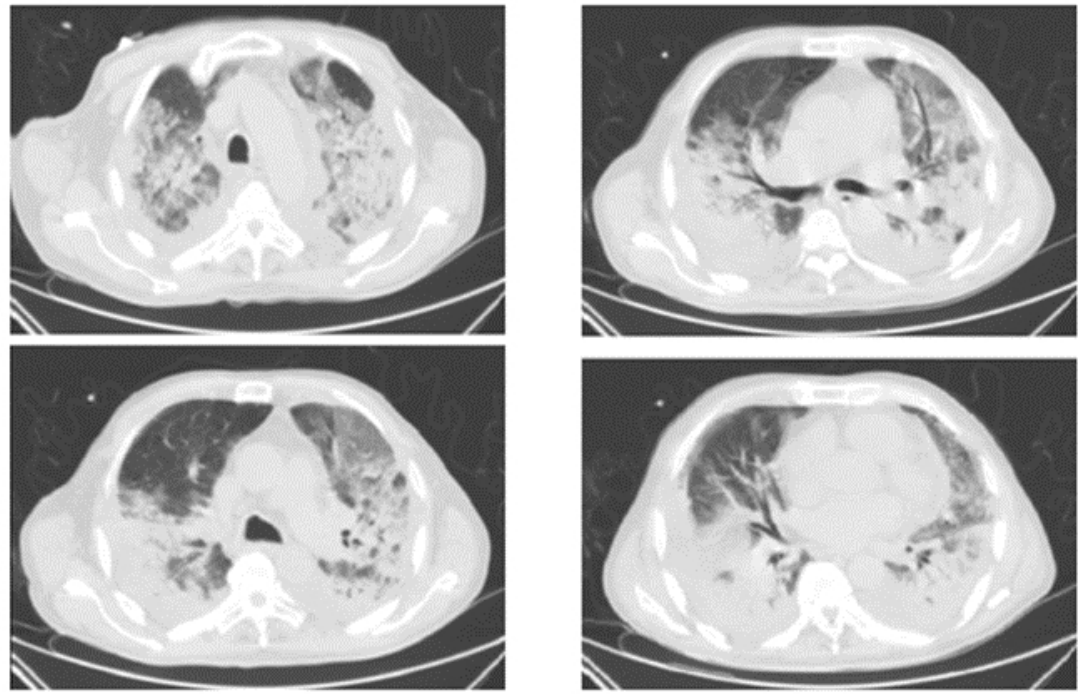

2. Simple thorax tomography at day 10 of stay in the ICU, after high-flow oxygen therapy.
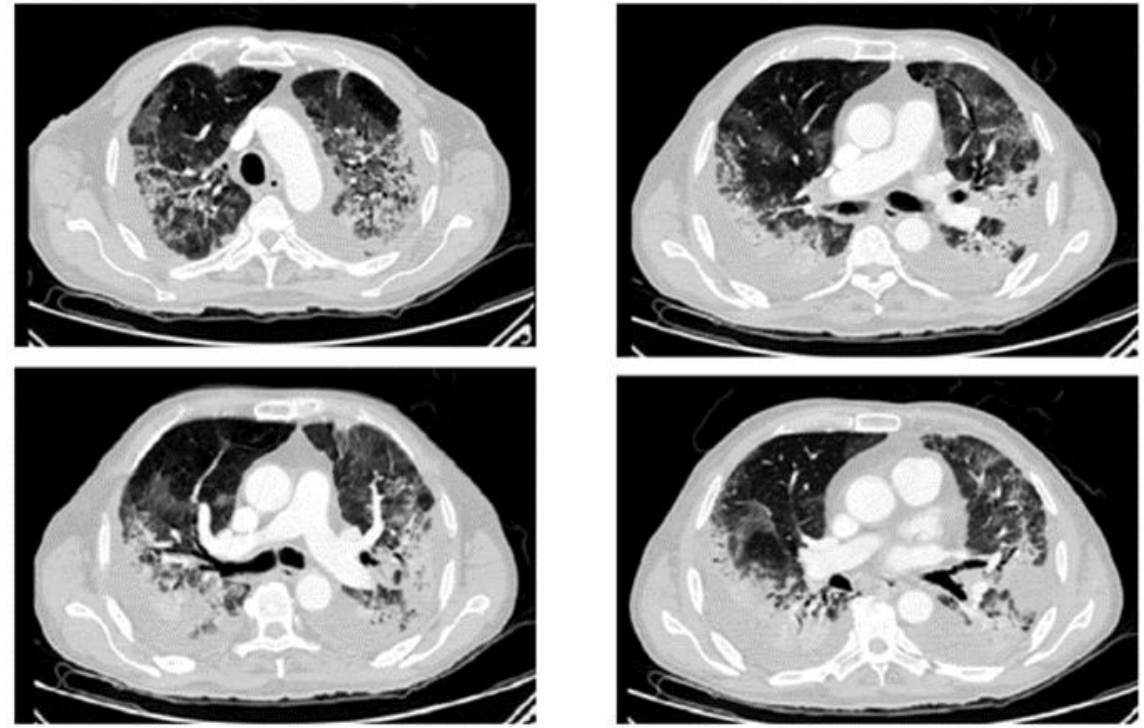

Image 3. Anterior-posterior thorax simple tomography studies performed during the internment of the patient in the ICU that show the radiographic evolution since the entry of the patient until his egress from the ICU. 


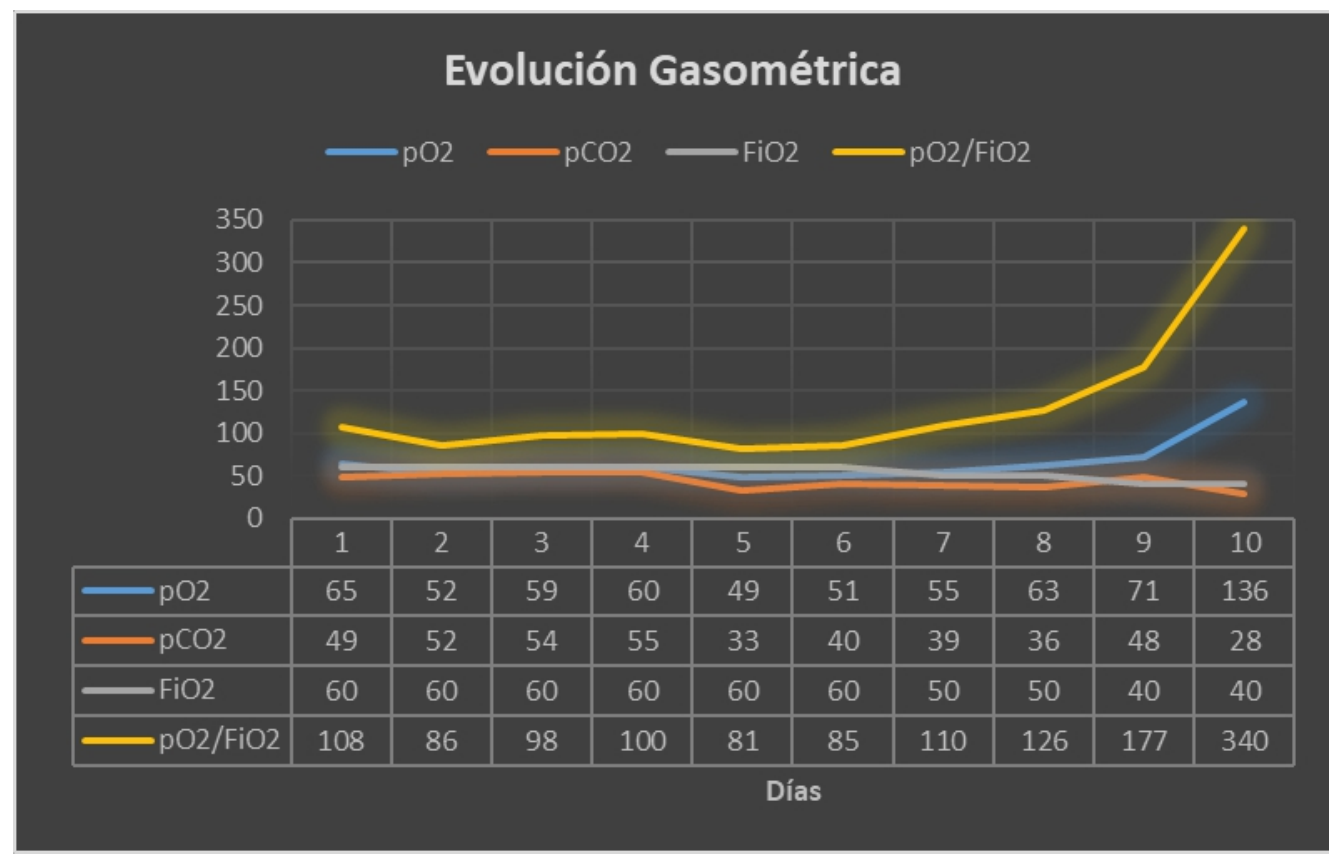

Image 4. $\mathrm{pO}_{2}$ : Arterial partial oxygen pressure. $\mathrm{pCO}_{2}$ : Arterial partial carbon dioxide pressure. $\mathrm{FiO}_{2}$ : Inspired oxygen fraction. The graph shows the behavior of gas exchange during the patient's evolution. The first two days he received oxygen through a reservoir mask and the oxygenation decrease is observed along with respiratory acidosis; later, the patient is treated with high-flow oxygen therapy and prone position, observing a transitory improvement until day 6 , where an important oxygen increase takes place, with an upturn in $\mathrm{PaO}_{2}$ and less need of inspired oxygen fraction.

\section{Discussion}

ARDS is a severe disease with an associated high mortality, it has been observed that both prone positioning and NHFO therapy benefit this patient population in patients with ARDS with $\mathrm{PaO} 2 / \mathrm{FiO} 2<150 \mathrm{mmHg}$. In this case, four important factors described above and the fact that LVEE increases in prone position using NHF therapy as a result of the recruitment of alveolar units, the authors decided to test the management of patients with acute ARDS (unrelated to COPD) with therapy with UFH and prone position. During the treatment of the 63-year-old case, the patient was monitored closely to detect any signs of impairment in order to scale attention as needed. The improvements in $\mathrm{ABG}$ and $\mathrm{SpO} 2$ seen with NHFO therapy were only significant, however, when the prone position was also adopted, the patient's WOB improved even more.

The patient and his relatives were kept informed of the practice strategy and understood to be a tool used with the objective of avoiding the need for mechanical ventilation. Of note and contrary to what has been previously described the $\mathrm{PaCO}_{2}$ did not decrease in response to prone position; 
however, the $\mathrm{PaO}_{2}$ did increase, along with $\mathrm{SaO}_{2}$, the decrease of the respiratory rate, and an improvement in dyspnea. As it is widely recommended to monitor the patient closely while receiving noninvasive mechanical ventilation, especiallywithin1 to 2 hours after the commencement of the treatment, the medical and nursing staff performed close surveillance for symptoms and vital signs of the patient. Should his condition worsen, treatment would be switched to invasive mechanical ventilation immediately; however, the trends always showed improvement.

The authors stress the fact that within the first 7 days of the high-flow oxygen therapy the possibility of delaying the invasive treatment was not discard or the patient deprived of the benefits of early mechanical ventilation. An evaluation was made in regard to the risk-benefit of limiting all the risks associated with the use of sedation, neuro-muscular blockage, opioid analgesia, and mechanical ventilation on its own. It was clearly understood that some patients with COPD can suffer complications with long-term mechanical ventilation, which is why the patient in this study was conservatively managed, which, in the end, showed the benefit of avoiding the use of mechanical ventilation.

The high-flow oxygen therapy and prone position were sufficient to treat a case of severe ARDS, eliminating the need for using invasive mechanical ventilation. However, the authors cannot recommend their use for this level of severity in a routine manner, which is why controlled studies of selected comparative cases must be undertaken using invasive mechanical ventilation. The authors note that there is a clinical trial in progress ClinicalTrials.gov Identifier: NCT03095300.

\section{Conclusion}

The prone position is a strategy that has shown a significant decrease in mortality in patients with ARDS, and it is a promising therapy for patients with spontaneous ventilation with high-flow oxygen therapy and an alternative to avoid invasive mechanical ventilation; controlled and randomized studies should be done to demonstrate its safety and efficacy.

\section{References:}

1. Matthay MA, Ware LB, Zimmerman GA. (2012) The acute respiratory distress syndrome .J Clin Invest. 122(8):2731-2740. doi:10.1172/JCI60331

2. Villar J, Sulemanji D, Kacmarek RM. (2014) The acute respiratory distress syndrome: incidence and mortality, has it changed? Curr Opin Crit Care. 20:3-9.doi:10.1097/MCC.0000000000000057

3. Lam E, Claudia C. (2008) Advances in molecular acute lung injury/acute respiratory distress syndrome and ventilator-induced lung 
injury: the role of genomics, proteomics, bioinformatics, and translational biology. Current Opinion in Critical Care . 14:3-10.doi: 10.1097/MCC.0b013e3282f42211

4. Smith LS, Zimmerman JJ, Martin TR. (2013) Mechanisms of Acute Respiratory Distress Syndrome in Children and Adults: A Review and Suggestions for Future Research.Pediatrics Crit Care Med. 14:631643.doi: 10.1097/PCC.0b013e318291753f

5. Capelozzi VL.(2008). What have anatomic and pathologic studies taught us about acute lung injury and acute respiratory distress syndrome? Current Opinion in Critical Care; 14:56-63

6. Villar J, Blanco J, Kacmarek RM. (2011) Acute respiratory distress syndrome definition: do we need a change? Current Opinion in Critical Care. 17:13-17.doi:10.1097/MCC.0b013e32834271fb

7. Costa ELV, Amato MB. (2013) The new definition for acute lung injury and acute respiratory distress syndrome: is there room for improvement? Curr Opin Crit Care, 19:000000.doi:10.1097/MCC.0b013e32835c50b1

8. Ranieri VM, Rubenfeld GD, Thompson BT. (2012) Acute Respiratory Distress Syndrome:The Berlin Definition. JAMA. 307(23):25262533. doi:10.1001/jama.2012.5669

9. O’Driscoll R. (2012) Emergency oxygen use. BMJ. 345:e6856. doi: 10.1136/bmj.e6856

10. Kallstrom TJ. (2002) AARC Clinical Practice Guideline: oxygen therapy for adults in the acute care facility 2002 revision \& update. Respir Care, 47(6):717-20

11. Messika J1, Ben Ahmed K2, Gaudry S1, Miguel-Montanes R2, Rafat C2, Sztrymf B3, Dreyfuss D1, Ricard JD4. (2015) Use of High-Flow Nasal Cannula Oxygen Therapy in Subjects With ARDS: A 1-Year Observational Study. Respir Care. 60(2):162-9. doi: 10.4187/respcare.03423.

12. Roca, Oriol. (2016) Current evidence for the effectiveness of heated and humidified high flow nasal cannula supportive therapy in adult patients with respiratory failure. Critical care. 20,1 109. 28, doi:10.1186/s13054-016-1263-z)

13. Medina A, Modesto V (2015) Seriously, Should We Be Treating Severe ARDS With High-Flow Nasal Cannula Oxygen? Respir Care 60: e148

14. Parke A. (2009) Nasal high-flow therapy delivers low level positive airway pressure British journal of anaesthesia. 103,6: 886-90

15. Möller W. (2015) Nasal high flow clears anatomical dead space in upper airway models Journal of applied physiology. 118,12: 1525-32.) 
16. Parke A. (2011) Preliminary Randomized Controlled Trial to Assess Effectiveness of Nasal High-Flow Oxygen in Intensive Care Patients Respiratory Care. $56 \quad$ (3) 265-270; DOI: https://doi.org/10.4187/respcare.00801.

17. Maggiore SM1, Idone FA, Vaschetto R, Festa R, Cataldo A, Antonicelli F, Montini L, De Gaetano A, Navalesi P, Antonelli M. (2014). Nasal high-flow versus Venturi mask oxygen therapy after extubation. Effects on oxygenation, comfort, and clinical outcome. Am J Respir Crit Care Med. 1;190(3):282-8. doi: 10.1164/rccm.2014020364OC.

18. Bryan AC. (1974). Conference on the scientific basis of respiratory therapy. Pulmonary physiotherapy in the pediatric age group. Comments of a devil's advocate. Am Rev Respir Dis, 110 (2):143-144

19. Carteaux G, Millán-Guilarte T, De Prost N, Razazi K, Abid S, Thille AW, Schortgen F, Brochard L, Brun-Buisson C, Mekontso Dessap A.(2016) Failure of Noninvasive Ventilation for De Novo Acute Hypoxemic Respiratory Failure: Role of Tidal Volume. Crit Care Med. 44(2):282-90.

20. Jaber J; Chanques G, (2010) Postoperative Noninvasive Ventilation Boris J Anesthesiology. 112(2):453-461

21. L'Her E, Deye N, Lellouche F, Taille S, Demoule A, Fraticelli A, Mancebo J, Brochard L.(2005) Physiologic effects of noninvasive ventilation during acute lung injury. Am J Respir Crit Care Med. $1 ; 172(9): 1112$.

22. Mancebo J. (2016).Noninvasive Ventilation in Acute Hypoxemic Respiratory Failure: Songs of Love and Hate. Crit Care Med.. 44(2):444-6.

23. Nishimura M. (2015) High-flow nasal cannula oxygen therapy in adults. Journal of Intensive Care. 3:15.doi:10.1186/s40560-015-00845

24. Gattinoni L, Taccone P, Carlesso E, Marini JJ. (2013) Prone position in acute respiratory distress syndrome rationale, indications, and limits. Am J Respir Crit Care Med, 188(11):1286-1293

25. Guérin C, Reignier J, Richard JC (2013) Prone positioning in severe acute respiratory distress syndrome. N Engl J Med. 368(23):2159_ 2168

26. Riera J, Perez P, Cortes J, Roca O, Maclans JR, Rello J. (2012) Effect of High-Flow Nasal Cannula and Body Position on End-Expiratory Lung Volume: A Cohort Study Using Electrical Impedance Tomography. Respiratory Care . doi: 10.4187/respcare.02086 